\title{
CORONARY HEART DISEASE IN THE PRESENCE OF PULMONARY DISEASE
}

\author{
BY \\ ARTHUR J. THOMAS \\ From Llandough Hospital, United Cardiff Hospitals
}

Received May 25, 1957

In the course of our studies of pulmonary heart disease we have been impressed by the frequent co-existence of coronary heart disease noted at necropsy but less frequently recognized during life. Pulmonary disease even before the advent of heart failure, was readily recognized by its symptoms of dyspnœa and cough and by its radiological signs. The co-existent coronary heart disease was often symptomless, or if pain was present it required differentiating from pleuropulmonary pain. Radiology was able to help only by showing an enlarged left ventricle in some of the cases. It seemed that electrocardiography would be the best examination to reveal the presence of the coronary heart disease with pulmonary disease, but consideration of the electrocardiographic signs of both conditions immediately revealed difficulties of interpretation.

Such difficulties are exemplified in Fig. 1, 2, and 3. The patient whose electrocardiogram is shown in Fig. 1 had pure pulmonary heart disease which, in the space of three years, had produced

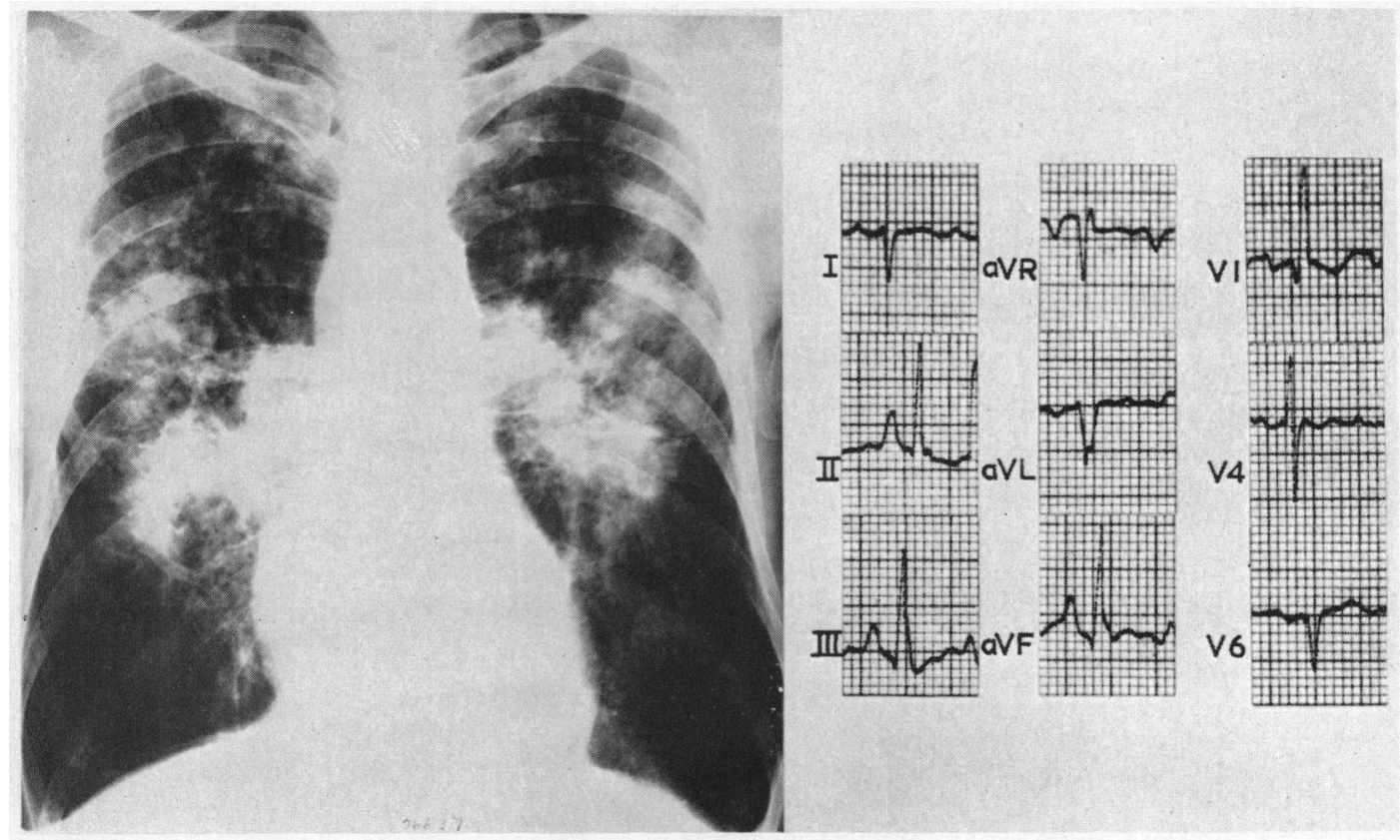

FIG. 1.-Man, aged 50 years. Pure pulmonary heart disease with its electrocardiographic pattern developing between 1952 and 1954. Width of QRS $=0.08 \mathrm{sec}$. 


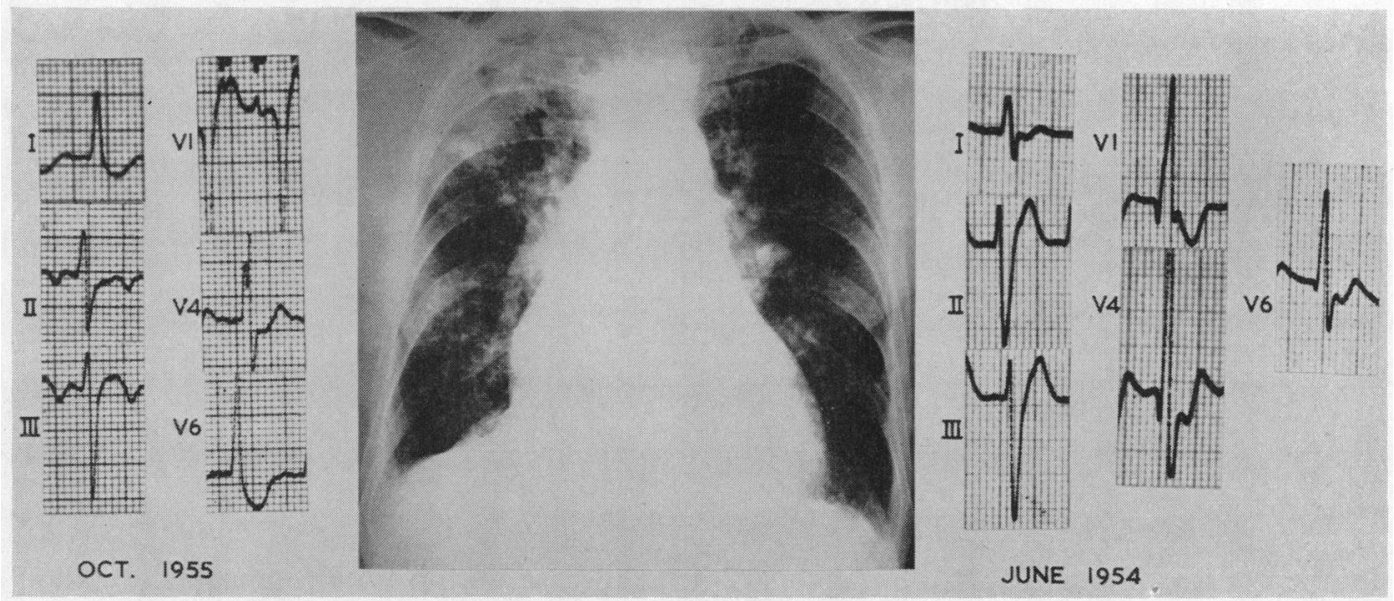

FIG. 2.-Man, aged 55 years, with coalworkers' pneumoconiosis and calcific aortic stenosis. The electrocardiogram changed on three occasions to a pattern of right bundle-branch block; QRS of width $0 \cdot 12$ sec.

right ventricular hypertrophy. In Fig. 2 are shown the electrocardiograms of a patient with cardiac pain on effort, an aortic systolic murmur, and a changing record, which at times suggested right ventricular hypertrophy or right bundle-branch block. This case was thought at one time to have coronary heart disease but at necropsy the coronary arteries were quite healthy, the left ventricular muscle was greatly hypertrophied, and the aortic valve calcified and stenosed. In the third example, depicted in Fig. 3, there was well-recognized pulmonary heart disease but also a systolic murmur, moderate hypertension, and a rather sudden change in the electrocardiogram between November, 1954, and March, 1955. At necropsy in December, 1955, the heart was $397 \mathrm{~g}$. in weight with the left ventricle weighing $164 \mathrm{~g}$. and the right ventricle weighing $110 \mathrm{~g}$. There was a small right coronary artery with severe atheroma, occlusion of the anterior descending branch

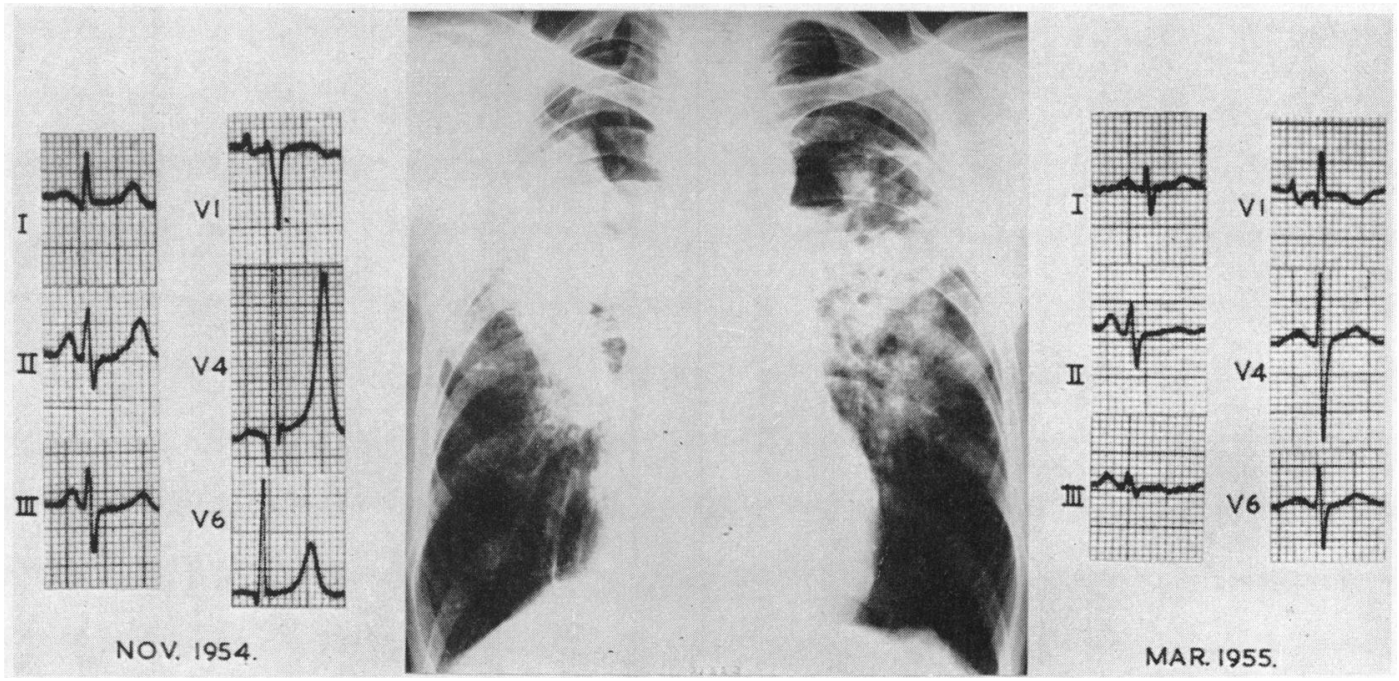

Fig. 3.-Man, aged 62 years, with coalworkers' pneumoconiosis and coronary heart disease. The electrocardiogram changed between November, 1954 and March, 1955 to a pattern of right ventricular hypertrophy or incomplete right bundle-branch block; QRS of width 0.09 sec. 
of the left coronary artery with infarction of the lower half of the interventricular septum. The change in the electrocardiogram was thought to result from the myocardial injury.

\section{Material ANd Method of Study}

These difficulties led us to carry out a correlation of the clinical features and the findings at necropsy in 69 patients with severe pulmonary disease. The cases selected for study have been miners or ex-miners because, by courtesy of the Pneumoconiosis Research Unit (M.R.C.), it has been possible to follow these in detail over a period of years. It is important to realize that the pulmonary disease was not only pneumoconiosis but often bronchitis and emphysema of the type seen also in non-industrial pulmonary disease. The other advantage of this clinical material was that long-term study of patients with pure pulmonary heart disease (Thomas, 1948 and 1951) had made us familiar with the variations of the symptoms, signs, and electrocardiograms in such cases.

Coronary heart disease has been regarded as present when there was evidence of myocardial damage macroscopically or on histological examination, with reduction by a third or more of the lumen of a major vessel; it has been considered present also without detectable myocardial damage in the presence of occlusion, recanalization, or extreme narrowing of a major coronary vessel.

A study of 69 patients has been made. Of these, 32 had clinical and necropsy evidence of coronary heart disease; 26 had doubtful evidence of coronary heart disease which was not confirmed at necropsy but other heart disease was revealed; the remaining 11 patients had significant coronary artery disease at necropsy that had not been diagnosed during life.

Of the 32 patients with proven coronary heart disease the average age at death was 62 years (46-74 years). They were divisible into two groups; 14 cases with frank myocardial infarction and 18 with severe coronary artery disease without frank infarction. The average heart weight of those with myocardial infarction was $455 \mathrm{~g}$. (340-700 g.), while those with severe coronary artery disease only it was $302 \mathrm{~g}$. (220-400 g.). The difference in weight was contributed by the left ventricle. The heavier hearts of those with myocardial infarction is in accord with the findings of Harrison and Wood (1949). In some of the cases there was right ventricular hypertrophy, but this applied equally to both groups and did not alter the difference.

\section{The Clinical Signs}

It is important to note that cardiac pain was not identified in five patients with myocardial infarction. There are several reasons for this; recurrent pleuro-pulmonary pain is frequent and it is not always easy to distinguish cardiac pain in a retrospective history; also, painless myocardial infarction does occur in syndromes of this kind. In those with coronary artery disease without infarction, five had cardiac pain on effort, but pulmonary disability restricted effort in some of the other cases and so masked any possible cardiac pain on effort.

Hypertension was not very common. If there was gross pulmonary fibrosis, the blood pressure tended to drop and in the last year or two of life might not be above $160 / 100 \mathrm{~mm}$. $\mathrm{Hg}$, even if it had been higher than this in earlier years. Whether the fall was due to loss of weight, to enforced rest, or to the cutting down of pulmonary blood flow was not clear.

\section{ELECTROCARDIOGRAPHY IN THE DIFFERENTIAL DiAGNOSIS}

The electrocardiographic signs of classical myocardial infarction need no comment. The presentation of the right bundle-branch block pattern caused difficulty but in this series it occurred more commonly with coronary heart disease than with pulmonary heart disease alone, in the proportion of five to one (Fig. 4). The numbers are small but they suggest that the identification of the cause of the right bundle-branch block pattern is important. In two instances the presence of abnormal $Q$ waves in lead III and S-T depression over the left ventricle suggested coronary artery disease with right bundle-branch block. There was difficulty with a high $\mathbf{R}$ wave in V1 without widening of the complex beyond $0.09 \mathrm{sec}$. as this could be due to right ventricular hypertrophy or incomplete right bundle-branch block. This finding develops slowly when due to right ventricular 
hypertrophy but suddenly in coronary heart disease, and it was on the score of this difference that the lesion shown cardiographically in Fig. 3 was thought to have arisen from coronary heart disease. Furthermore, coronary heart disease may be suspected if there is right bundle-branch block with no other evidence of right ventricular hypertrophy and no alternative explanation of its presence.

In this series the lesser electrocardiographic signs of myocardial injury (Evans and McRae, 1952) have been found of great value and the form of the S-T segment has been as important as its actual depression (Holzmann, 1952). Left axis deviation with S-T depression in lead I, a qR complex with $\mathrm{T}$ inversion in aVL, a trough or deep depression of $\mathrm{S}-\mathrm{T}$ segment and a low, blunt or flat $\mathrm{T}$ wave in $\mathrm{V} 6$ were present with coronary heart disease and these signs were not seen in pure pulmonary disease (Fig. 5 and 6). Right axis deviation with $\mathrm{S}-\mathrm{T}$ depression or $\mathrm{T}$ inversion in

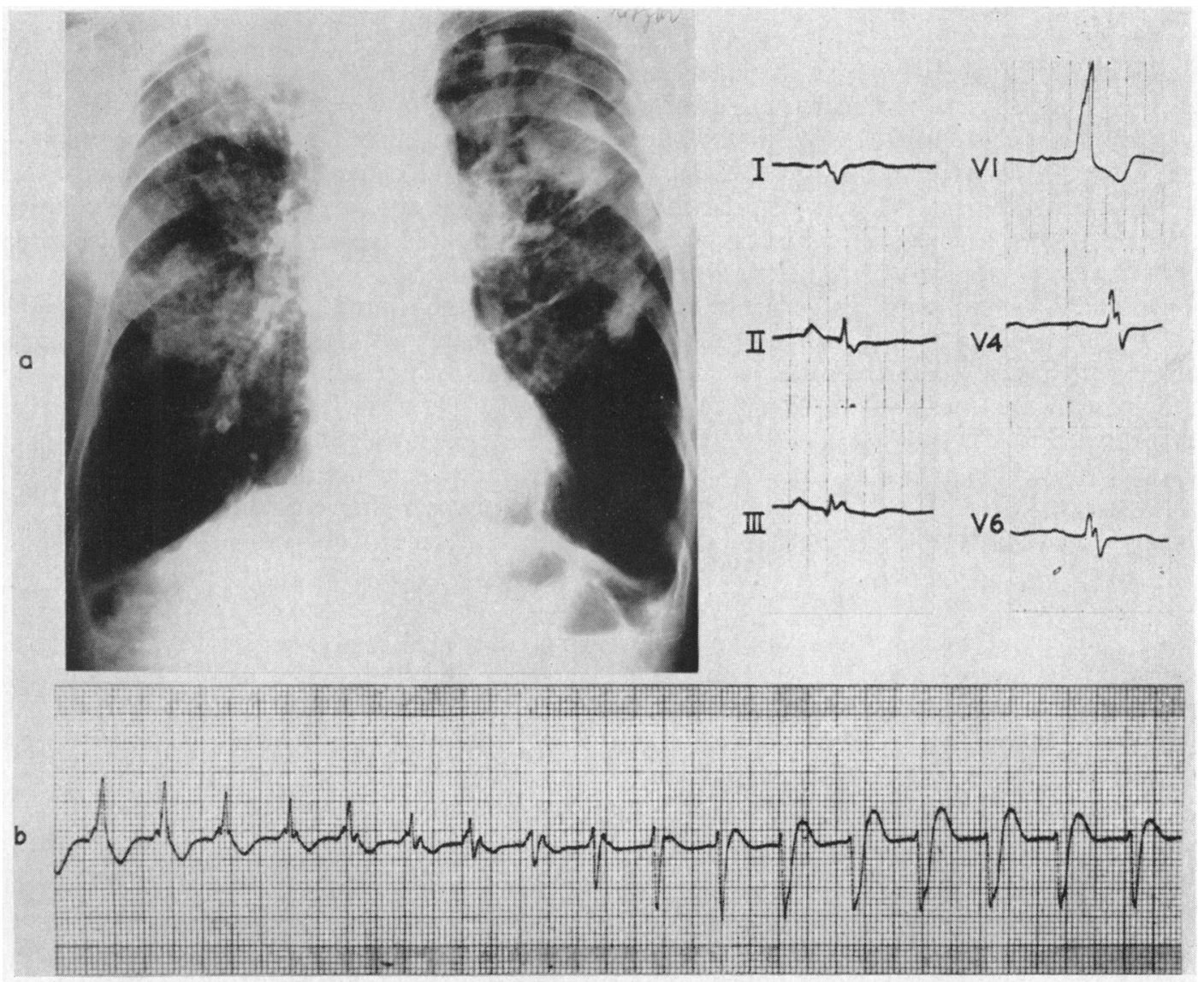

FIG. 4.- (a) Man, aged 62 years, with pulmonary disease and coronary heart disease. Electrocardiograph of right bundle-branch block (QRS of $0.12 \mathrm{sec}$.). The heart weighed $500 \mathrm{~g}$., with the right ventricle $7 \mathrm{~mm}$. and the left ventricle $16 \mathrm{~mm}$. in thickness.

(b) Man, aged 61 years, with bronchitis and emphysema, mitral incompetence, myocardial fibrosis, and coronary artery disease. Lead V1, showing pattern of changing intraventricular conduction. Heart weight $493 \mathrm{~g}$., the right ventricle $140 \mathrm{~g}$. and the left ventricle $208 \mathrm{~g}$.

leads III, aVF, and V6 was more difficult to interpret but the presence of S-T changes of trough or plane depression in V6 was usually associated with coronary heart disease and was not present in pure pulmonary heart disease unless there was extreme rotation or distortion. The type of $\mathrm{T}$ inversion in lead III was abnormal in some cases with the curved S-T segment and deep T wave 
inversion suggesting myocardial injury (Fig. 6). Auricular fibrillation was so extremely rare in pure pulmonary heart disease that it was regarded always as indicative of other heart disease, and in four patients of this series it was present with combined pulmonary and coronary heart disease.

In general, the pulmonary disease tends to produce an electrocardiogram denoting a vertical heart and aVL is then of QS or rS type with T wave inversion. When the aVL is of qR pattern the $\mathrm{S}-\mathrm{T}$ segment is isoelectric and the $\mathrm{T}$ upright in the normal or pulmonary case. Occasionally, an electrocardiogram has shown a $\mathrm{qR}$ complex in aVL with a curved $\mathrm{S}-\mathrm{T}$ segment convex upwards to an inverted $\mathrm{T}$ wave. On both occasions in this series this form of aVL has accompanied coronary heart disease and has not been present in the pure pulmonary heart disease group. A further series will be required to assess aVL but it would seem that a qR complex with S-T curving to $T$ inversion is an abnormality not associated with pulmonary heart disease but with concomitant coronary heart disease or left ventricular hypertrophy.

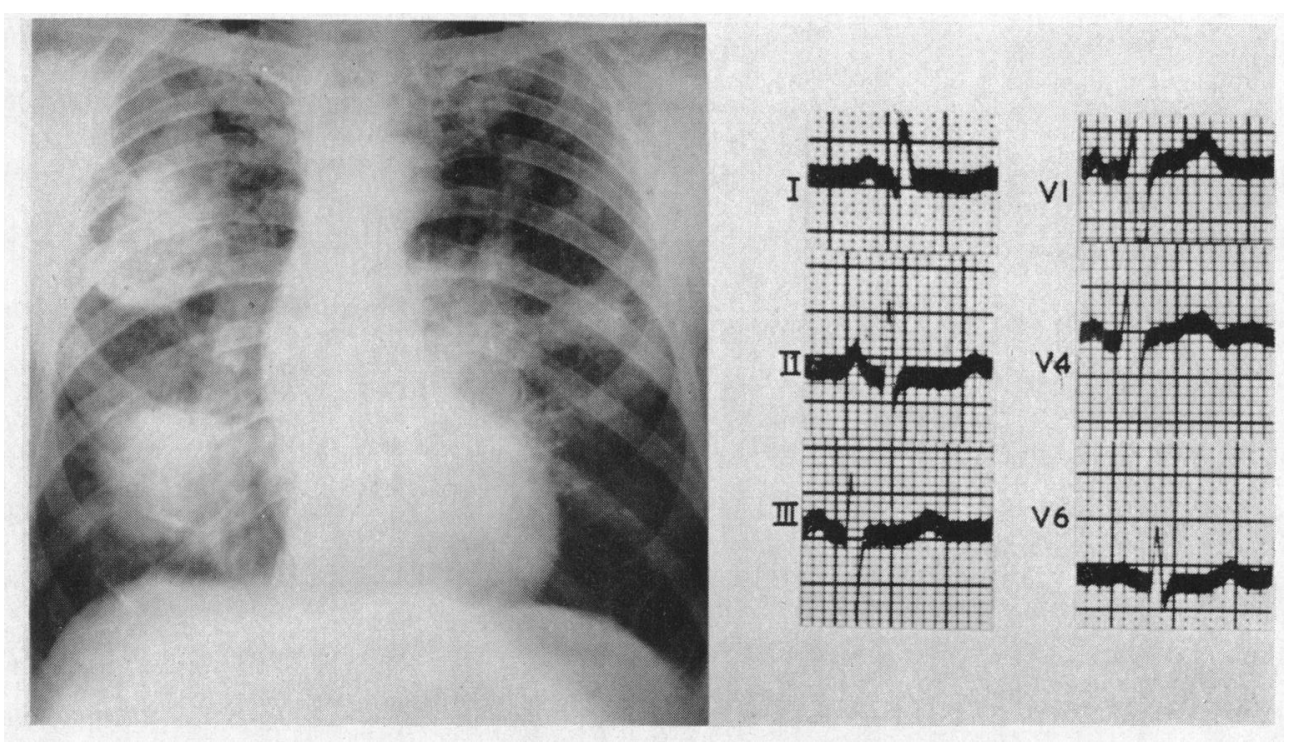

FIG. 5.-Man, aged 65 years, with coalworkers' pneumoconiosis and coronary heart disease. The heart weighed $340 \mathrm{~g}$. with the right ventricle $6 \mathrm{~mm}$. and the left ventricle $15 \mathrm{~mm}$. in thickness.

The simple changes of left axis deviation and blunt $\mathrm{T}$ waves from left ventricular leads cannot be taken as evidence of coronary heart disease as they may well be the result of left ventricular preponderance or hypertrophy, but they are quite unusual in fully developed pulmonary heart disease and may be regarded as indicators of some other heart disease affecting the left ventricle.

In many of these patients there were other clinical signs to support the diagnosis. There was cardiac pain in 14 cases; there was the helpful sign of left ventricular enlargement that could not be explained on other clinical grounds; and there were signs of atherosclerosis of the aorta and other vessels. Final assessment of the presence of coronary heart disease with pulmonary disease required the consideration of all these factors, together with the exclusion, if possible, of other causes of left ventricular hypertrophy. The electrocardiogram was of proven value in making the diagnosis.

\section{The Differential Diagnosis of Other Heart Diseases}

There were 26 patients suspected at some time, on clinical or electrocardiographic grounds, of having coronary heart disease but in whom this was not found at necropsy. These are worthy of analysis because of the other heart diseases present. In six of them the electrocardiogram was 
that of pure pulmonary heart disease, but doubt arose through clinical findings such as thoracic pain; necropsy revealed no heart disease. Two others were suspect because of the altered S-T segments and flat or inverted $\mathrm{T}$ waves in V4, but this sign was clearly compatible with pure pulmonary heart disease if the $\mathrm{T}$ wave was upright in V6.

The other 18, in all of whom the doubtful sign was in the electrocardiogram, were distributed as follows:

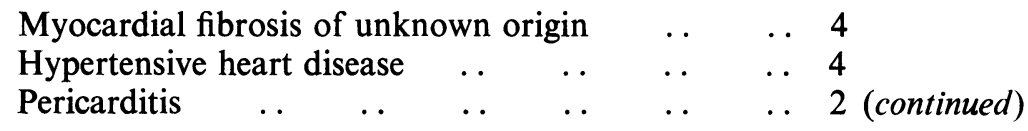

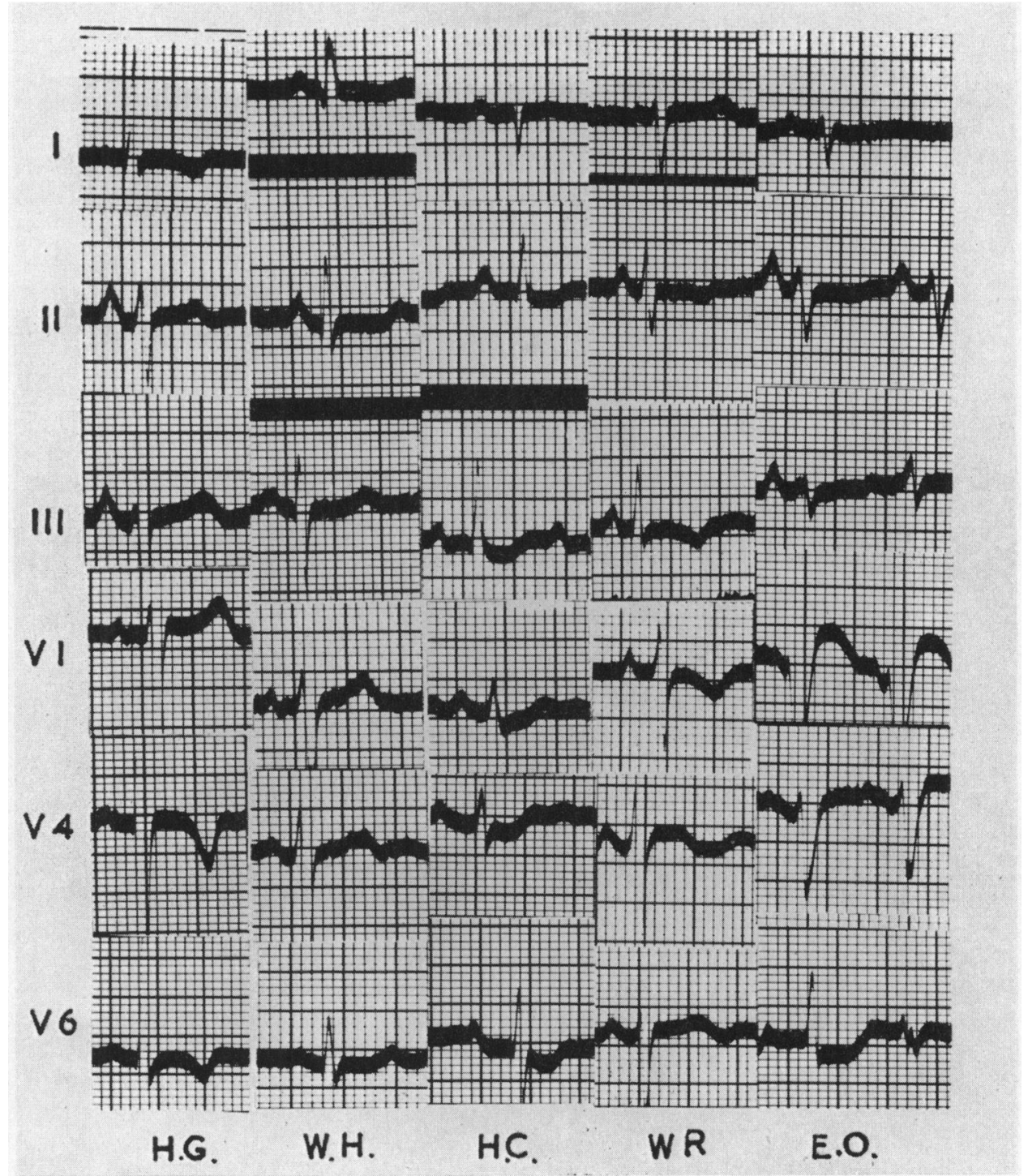

FIG. 6.-Five examples of electrocardiograms in proven pulmonary disease and coronary heart disease. The departures from the usual pulmonary heart pattern are considered to be due to the effect of coronary heart disease. 


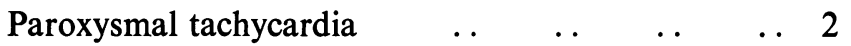

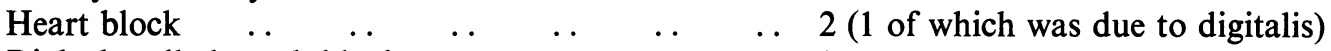

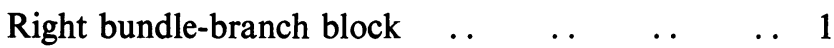

Flat $\mathrm{T}$ waves in the electrocardiogram $\quad . \quad \ldots \quad$. 3

On retrospective scrutiny the cases of myocardial fibrosis and those of heart block would still be suspected of coronary heart disease, because of the form of the electrocardiogram or the radiological prominence of the left ventricle. Transient prolongation of the $P-R$ interval has been seen in pure pulmonary heart disease and is not regarded as due to myocardial injury. The clinical findings have helped to establish the presence of hypertensive heart disease, aortic stenosis, and pericarditis, but electrocardiography alone could be confusing when these conditions co-existed with severe pulmonary disease (Fig. 2). Difficulty arises from the occasional appearance of flat $T$ waves in the electrocardiogram of pure pulmonary disease, and this is not fully explained yet. This group of cases indicates the difficulty that may arise in the recognition of coronary heart disease when other heart diseases may also be present.

\section{The Non-Recognition of Coronary Artery Disease}

There were 11 patients who at necropsy had significant coronary artery disease that had not been discovered during life. In three of them there was marked right ventricular hypertrophy and this appeared on the electrocardiogram, but the leads recorded did not reveal the left ventricular pattern properly, although they included præcordial leads to V6. In two other cases it was likely that the electrocardiograms were taken before the final changes due to coronary heart disease had appeared. One other patient had been accepted as having hypertensive heart disease. The five remaining had severe coronary artery disease but they had not produced any recognizable clinical picture or electrocardiographic abnormality when death occurred from other causes. The average heart weight in this group of 11 cases was $323 \mathrm{~g}$. (220-397 g.), and was similar to the first group recognized as having coronary artery disease without frank myocardial infarction.

The findings in these 11 patients suggest that detection of coronary heart disease with pulmonary disease requires repeated electrocardiograms, especially in episodes of pulmonary infection; the leads recorded must include those derived from the left ventricle which may be situated more posteriorly than usual. Even so, severe coronary artery disease is present occasionally without affecting the myocardium and so is clinically silent.

\section{Discussion}

As chronic pulmonary disease occurs so often in middle age or later, it coincides with the period of high prevalence of coronary artery disease. Both of these diseases affect the heart and, as suggested by Drake (1951), they may exert an unfavourable influence one on the other. The diagnosis may not be made completely, and the disease most likely to pass unnoticed clinically is that of the coronary arteries. There is no suggestion as yet that chronic pulmonary disease predisposes to a higher prevalence of coronary disease, but both may be unduly prevalent in the population studied in this work.

The detection of coronary heart disease is made easier once the suspicion of its presence has arisen. The finding of cardiac pain is of great value, but because pleuro-pulmonary pain is common in chronic respiratory disease, attention has to be paid to all the criteria for identifying cardiac pain. These have been reviewed by Master et al. (1954).

In the study of the effects of pulmonary disease on the heart, I have been impressed by the rarity of left ventricular enlargement or hypertrophy in pure pulmonary heart disease. Thus, if it is found, another explanation of the increased size of the left ventricle must be sought. In this work, the heavier left ventricle has been associated with myocardial infarction in a number of cases.

Aortic stenosis, of mild degree, is not uncommon in the later age groups and appears at times in association with severe pulmonary disease. Two things have happened: aortic stenosis has 
mimicked myocardial infarction and also, in an earlier series, a case of proven calcific aortic stenosis with advanced pulmonary disease eventually died of coronary occlusion. It is clearly important to assess the heart from the standpoint of a possible aortic stenosis before identifying coronary heart disease.

The other cause of left ventricular enlargement that has to be analysed is hypertension. This analysis is rendered difficult because severe anoxia in the pulmonary disease elevates the blood pressure to considerable heights for short periods. This hypertension, however, does not affect the left ventricle or the left ventricular pattern of the electrocardiogram. On the other hand, patients. with severe pulmonary fibrosis and known systemic hypertension have lost the high blood pressure readings in the last year of their illness, but signs of the hypertrophied left ventricle have remained, particularly in the electrocardiogram.

The finding of four examples of myocardial fibrosis with left ventricular enlargement and no detectable cause is surprising and demands further investigation.

The electrocardiogram has been of the greatest help in the diagnosis of coronary heart disease in the presence of pulmonary disease. It has revealed unsuspected coronary heart disease and has explained the unusual behaviour in some cases of pulmonary heart failure. However, the pattern of right ventricular hypertrophy can resemble that of myocardial infarction and cause difficulty (Myers, 1950). The electrocardiogram has recorded myocardial injury or ischæmia in some form and it is not surprising that the occasional case of myocardial fibrosis of unknown origin appears with the diagnosis of coronary heart disease. Left ventricular hypertrophy needs to be differentiated from coronary heart disease in the electrocardiogram but in many instances this has been possible. The changes in various forms of heart block have been confusing, but the interesting finding is that the right bundle-branch block pattern has appeared more frequently because of coronary heart disease than of pure pulmonary disease.

Further application of the electrocardiogram, particularly with detection of the lesser changes of myocardial injury (Evans and McRae, 1952), should prove of great interest in cases of pulmonary disease. The exercise tests have not proved helpful when there is severe pulmonary disease because the dyspnœic patient is already applying the equivalent of an exercise test to himself, but if the pulmonary disease is slight then the exercise test has taken its proper place. The ballistocardiographic pattern was not helpful as the complexes were greatly reduced in amplitude and changed in form by the pulmonary disease and by the coronary heart disease without there being distinguishing features.

This work has drawn our attention to the need for detailed analysis of all the findings in chronic pulmonary disease to exclude co-existent heart disease, particularly coronary heart disease.

\section{SUMMARY}

A review of the clinical features, electrocardiographic patterns, and necropsy findings in 69 cases of severe pulmonary disease shows the problem of the diagnosis of co-existing coronary heart disease. In 32 coal workers with severe pulmonary disease and necropsy proof of coronary heart disease the diagnosis could be made from clinical and electrocardiographic signs. Cardiac pain required differentiation from pleuro-pulmonary pain but was not always present. Myocardial infarction was accompanied by an increase in size and weight of the left ventricle. Five groups of electrocardiographic patterns were selected as indicative of coronary heart disease in the presence of pulmonary disease, but certain difficulties were recognized. These groups were (a) the electrocardiogram of frank myocardial infarction; (b) the pattern of bundle-branch block when this was not considered due to right ventricular hypertrophy or when signs were seen of myocardial infarction with the bundle-branch block; (c) left axis deviation with S-T changes and T wave inversion in left ventricular leads; (d) right axis deviation with the presence of significant S-T depression in left ventricular leads and occasionally in these cases a $\mathrm{qR}$ in aVL with $\mathrm{T}$ wave inversion; and (e) the presence of auricular fibrillation when other heart disease was not present to explain it. Difficulties arose in the recognition of other causes of left ventricular enlargement, such as aortic stenosis or 
myocardial fibrosis of unknown origin, and in the identification of the causes of various degrees of heart block. It is clear that with serial electrocardiograms by paying attention to the interpretation of the lesser electrocardiographic signs of myocardial injury, the accuracy of diagnosis of coronary heart disease can be greatly increased even in the presence of severe pulmonary disease. Some of the errors that occur would seem to be at the present moment unavoidable, but require further study.

Some of our patients had coronary artery disease that was clinically silent and in these cases a diagnosis before necropsy could not be expected. It is evident that the presence of coronary heart disease will generally modify the clinical picture of pulmonary heart disease; it may account in part for unexpected cardiac findings; or it may hasten the end. It is therefore worth while investigating critically for coronary heart disease all patients with chronic pulmonary disease.

I am greatly indebted to Dr. J. C. Gilson, Director of the Pneumoconiosis Research Unit (M.R.C.), for access to the clinical material; to Professor J. Gough and his staff, Department of Pathology, Welsh National School of Medicine, and Dr. J. Rivers for the necropsy studies; and to Mr. L. Williams for the illustrations.

\section{REFERENCES}

Drake, E. H. (1951). Ann. intern. Med., 35, 600.

Evans, W., and McRae, C. (1952). Brit. Heart J., 13, 457.

Harrison, C. V., and Wood, P. H. (1949). Brit. Heart J., 11, 205.

Holzmann, M. (1952). Clinical Electrocardiography. Translated by Robertson, D., Staples Press, London.

Master, A. M., Jaffe, H. L., and Pordy, L. (1954). Ann. intern. Med., 41, 315.

Myers, G. B. (1950). Circulation, 1, 860.

Thomas, A. J. (1948). Brit. Heart J., 10, 282.

- (1951). Brit. Heart J., 13, 1. 